\title{
Conference Paper \\ Synthesis and Characterisation of Thin Films of Bismuth Triiodide for Semiconductor Radiation Detectors
}

\author{
Alka Garg, ${ }^{1}$ Monika Tomar, ${ }^{2}$ and Vinay Gupta ${ }^{3}$ \\ ${ }^{1}$ Gargi College, University of Delhi, Siri Fort Road, New Delhi 110049, India \\ ${ }^{2}$ Miranda House, University of Delhi, Delhi 110007, India \\ ${ }^{3}$ Department of Physics and Astrophysics, University of Delhi, Delhi 110007, India \\ Correspondence should be addressed to Alka Garg; alkagargi67@yahoo.com
}

Received 7 February 2014; Accepted 18 March 2014; Published 2 April 2014

Academic Editors: P. Mandal, R. K. Shivpuri, and G. N. Tiwari

This Conference Paper is based on a presentation given by Alka Garg at "National Conference on Advances in Materials Science for Energy Applications" held from 9 January 2014 to 10 January 2014 in Dehradun, India.

Copyright (C) 2014 Alka Garg et al. This is an open access article distributed under the Creative Commons Attribution License, which permits unrestricted use, distribution, and reproduction in any medium, provided the original work is properly cited.

\begin{abstract}
Bismuth iodide is a potentially active material for room temperature radiation detector, as it is well reported in the literature that it has both wide energy band gap and high atomic absorption coefficient. Crystalline films of high atomic number and high radiation absorption coefficient can absorb the X-rays and convert them directly into electrical charges which can be read by imaging devices. Therefore, it was proposed to grow thin films of Bismuth iodide on glass substrate using thermal evaporation technique in vacuum to avoid the inclusion of impurities in the films. The structural studies of the films were carried out using XRD and optical absorption measurement was carried out in the UV/VIS region using spectrophotometer. All Bismuth iodide films grown at room temperature are polycrystalline and show X-ray diffraction peaks at angles reported in research papers. The optical transmission spectra of $\mathrm{BiI}_{3}$ films show a high transmission of about $80 \%$ in visible region with a sharp fall near the fundamental absorption at $650 \mathrm{~nm}$. Resistivity of the as-grown film was found to be around $10^{12} \mathrm{ohm}-\mathrm{cm}$ suitable value for X-ray detection application. Films were subjected to scanning electron microscopy to study the growth features of both as-grown and annealed films.
\end{abstract}

\section{Introduction}

Gamma ray detectors have become increasingly important for the application of medical imaging and environmental safety. Photographic films, Phosphor screens, and Silicon array have been used as imaging detectors for many years but all these devices are indirect detectors with low efficiency and poor spatial resolution. Compound semiconductors are the most promising radiation detector compared to high purity Ge and Si because of their moderate band gap and ability to operate at room temperature [1]. Bismuth iodide is one such compound semiconductor with potential for room temperature gamma and X-ray detection applications [2]. Bismuth Triiodide is having both high atomic number and high absorption coefficient, important parameters for material to detect X-rays and Gamma rays [3]. Bismuth
Triiodide is a layered compound having low melting point of $408^{\circ} \mathrm{C} . \mathrm{BiI}_{3}$ is stable within the range from melting point to room temperature [4]. $\mathrm{BiI}_{3}$ is reported to have vapor pressure of around $90 \mathrm{mbar}$ at temperatures $250^{\circ} \mathrm{C}$ to $300^{\circ} \mathrm{C}$ $[5,6]$. Therefore, $\mathrm{BiI}_{3}$ films can be grown from both liquid and vapour phases. $\mathrm{BiI}_{3}$ has been reported with different band gap characteristics and values. Experimentally and computationally, band gap value is ranging from $1.5 \mathrm{eV}$ to $2.2 \mathrm{eV}$ [7]. It is reported that $\mathrm{BiI}_{3}$ has both direct and indirect band gaps.

The aim of the present work is to prepare polycrystalline thin films of Bismuth Triiodide by thermal evaporation method and study the optical and structural properties of the material to present preliminary results which would be in future help in developing Bismuth iodide as room temperature radiation detector. 


\section{Experimental}

Bismuth Triiodide films were grown on glass substrate $(2 \mathrm{~cm} \times 6 \mathrm{~cm})$ at room temperature by conventional thermal evaporation technique using molybdenum boat at a pressure approximately $10^{-6}$ Torr. Starting material (99.99\% purity) procured from Aldrich chemicals was used for growing films. Uniformity and thickness of the films were found out using DEKTAK 150 surface profiler. The deposition rate was maintained to be slow around $5-6 \mathrm{~nm} / \mathrm{s}$ as the higher deposition rate led to nonuniform film growth and low sticking adherence to the glass substrate.

Structural analysis of the as-grown and annealed films was carried out using X-ray diffraction using Bruker D8 XRD. Optical transmission spectra of the annealed and as-grown Bismuth Triiodide films deposited on the glass substrate were recorded as a function of wavelength in the range (200$1100) \mathrm{nm}$ at room temperature using Perkin Elemer, lamda 35 UV/VIS spectrometer. Surface morphology of the films has been studied through scanning electron microscope (SEM MIRA3TESCAN)) to ascertain the uniformity of as-grown and annealed films. The resistivity of films was measured using Keitheley semiconductor analyser (SCS 4200).

\section{Result and Discussion}

The as deposited $\mathrm{BiI}_{3}$ films were found to be smooth and strongly adhered to the substrate surface. The as-grown films were polycrystalline and stoichiometric (as per X-ray diffraction). Figure 1 shows the XRD pattern of as grown Bismuth Triiodide films. Sharp and well-defined reflections corresponding to (003), (006), (008), (009), (300), (0010), and (0012) planes of $\mathrm{BiI}_{3}$ were observed at around $2 \theta=12.79^{\circ}$, $25.78^{\circ}, 26.99^{\circ}, 35.27^{\circ}, 39.09^{\circ}, 41.59^{\circ}, 43^{\circ}$ and $52.99^{\circ}$, respectively, which are in good agreement to the corresponding reflections reported in the PCPDF card number 76-1742. The XRD analysis shows a high degree of orientation with basal plane parallel to substrate and $c$-axis normal to the substrate. On annealing, the intensity of certain peaks are increasing along with appearance of planes. The crystalline size of the asgrown and annealed film was estimated by fitting the FWHM of dominant (003) plane using Scherrer's formula:

$$
d=\frac{K \lambda}{\beta \operatorname{Cos} \theta},
$$

where $K$ is $0.94, \lambda$ is $\mathrm{X}$-ray wavelength, $\beta$ is FWHM, and $\theta$ is diffraction peak position. The estimated value of crystallite size is about $32 \mathrm{~nm}$. On annealing the films, decrease in FWHM from approximately from 0.2470 to 0.2006 manifests an improvement in the crystalline quality and enlargement of grain size from around $32 \mathrm{~nm}$ to $40 \mathrm{~nm}$.

Figure 2 shows the optical transmittance spectrum of the $\mathrm{Bil}_{3}$ films deposited on the glass substrate. Films exhibit a high optical transmission (80\%) in the visible range and show a sharp fundamental absorption edge at around $650 \mathrm{~nm}$. The presence of well-defined interference pattern in the optical transmittance spectra indicates the growth of uniform good quality $\mathrm{BiI}_{3}$ film free from any inhomogeneity which is also

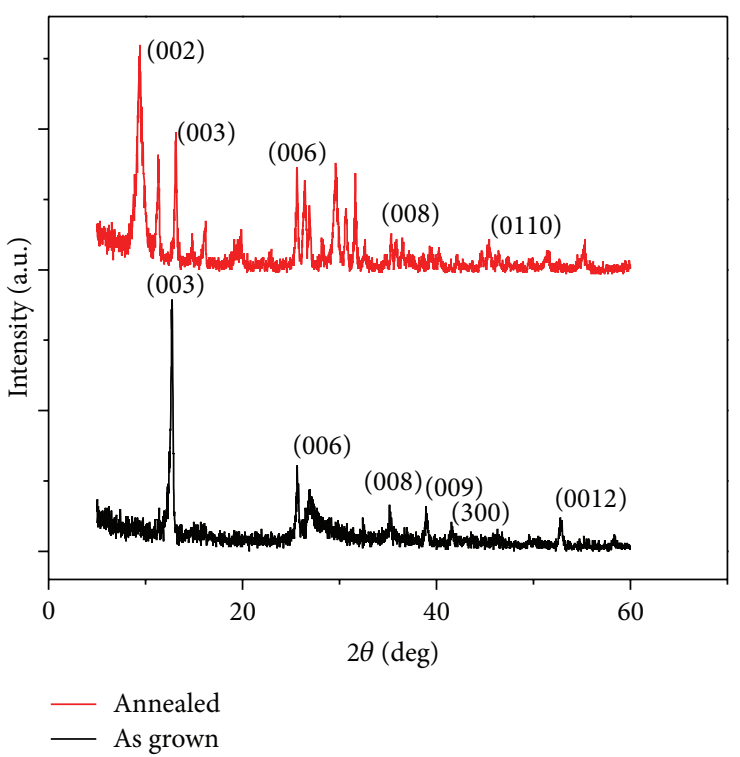

FIGURE 1: XRD of as-grown and annealed films of Bismuth TriIodide.

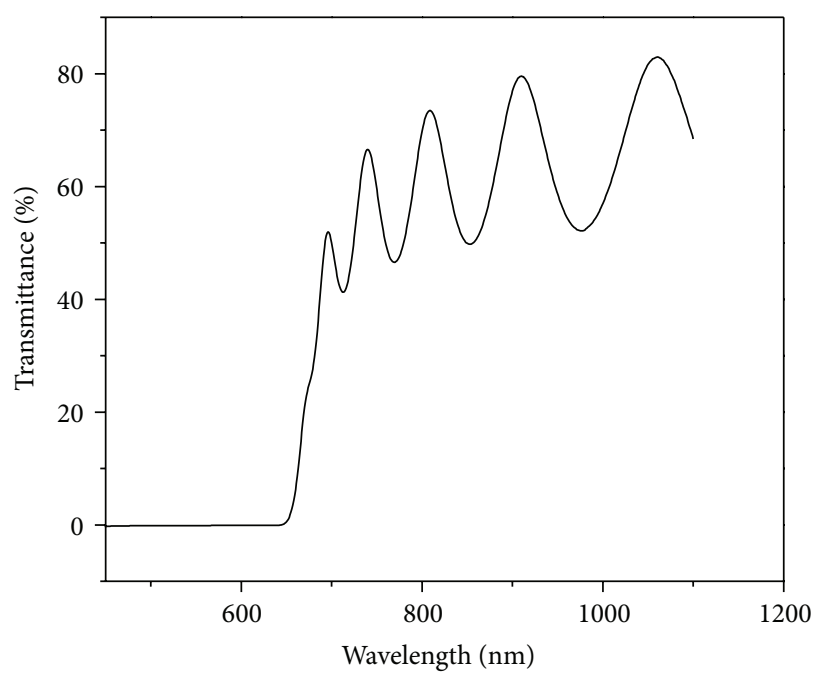

FIgURE 2: Optical transmission spectra of as-grown $\mathrm{BiI}_{3}$ thin film.

well explained by sharp reflections in the XRD pattern. The value of optical band gap $\left(E_{g}\right)$ was estimated from the linear portion of the Tauc plot (Figure 3) between $(\alpha h \nu)^{2}$ with photon energy $(h \nu)$, where $\alpha$ is the absorption coefficient and $v$ is the optical frequency. The value of $E_{g}$ was found to be about $1.82 \mathrm{eV}$ which is close to the corresponding reported value for $\mathrm{BiI}_{3}$ thin film by other workers.

Scanning electron microscope (SEM) micrographs are shown in Figures 4 and 5. The surface morphology of $\mathrm{BiI}_{3}$ is of uniform nature having nanocrystalline size grains whose sizes are close to the grain size reported from XRD. Films on annealing appear to be highly oriented suggesting micrograins aligned themselves to grow parallel to the substrate [8]. Also, it appears that film is grown by layer growth mechanism 


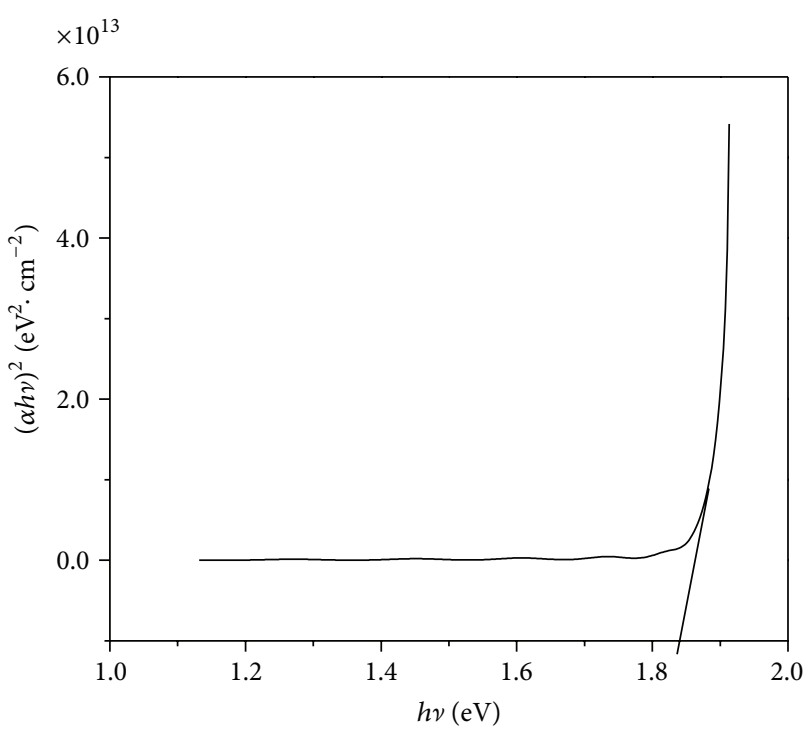

Figure 3: Tauc plot of BiI3 thin film.

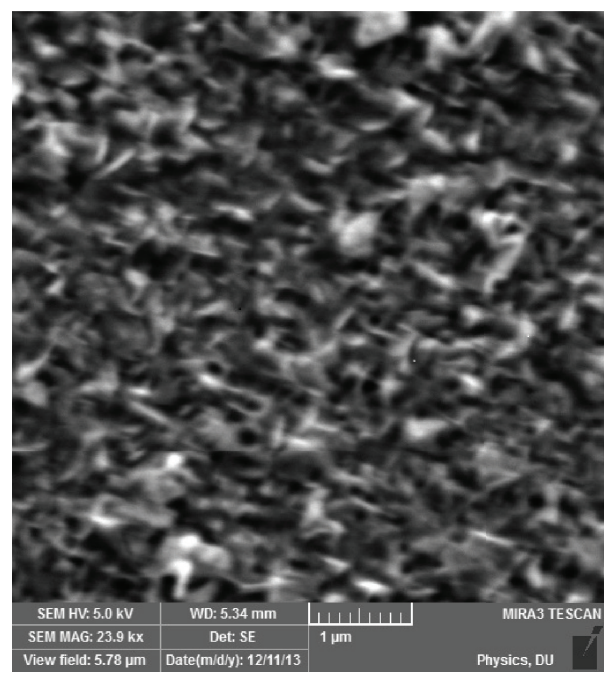

FIGURE 4: SEM micrograph of as-grown film of Bismuth Triiodide.

which is a characteristic property of layered compounds like Bismuth Triiodide.

\section{Conclusion}

$\mathrm{BiI}_{3}$ thin films were grown by thermal evaporation technique. Structural, morphological, and optical properties of thin films were studied by XRD, SEM, and UV-visible spectroscopy, respectively. It was observed that the films were polycrystalline with hexagonal nature and grain size increased upon annealing the films at $100^{\circ} \mathrm{C}$. Also, on annealing microcrystalline grains arranged themselves periodically indicating improvement in the crystalline quality of the film.

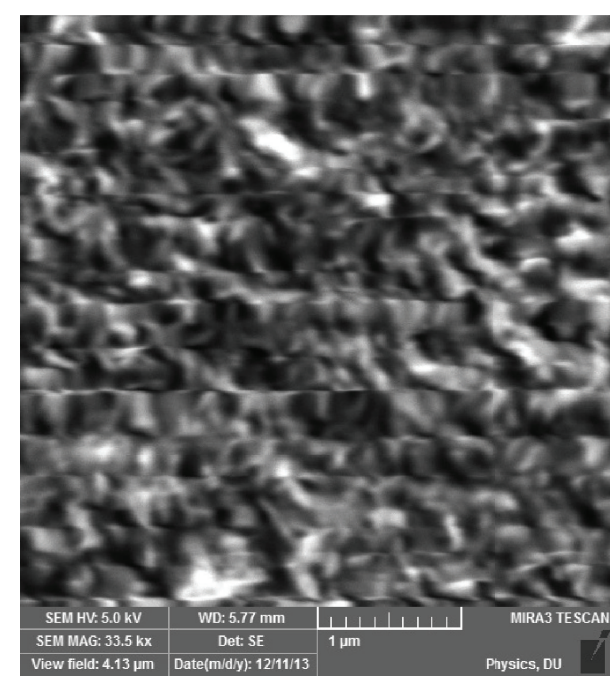

FIgURE 5: SEM micrograph of annealed film of Bismuth Triiodide.

\section{Conflict of Interests}

The authors declare that there is no conflict of interests regarding the publication of this paper.

\section{References}

[1] P. J. van Heerden, The crystal counter [Ph.D. thesis], Utrecht University, 1945.

[2] M. Matsumoto, K. Hitomi, T. Shoji, and Y. Hiratate, "Bismuth tri-iodide crystal for nuclear radiation detectors," IEEE Transactions on Nuclear Science, vol. 49, no. 5, pp. 2517-2520, 2002.

[3] P. R. Bennet, K. S. Shah, L. J. Cirignano, M. B. Klugerman, L. P. Moy, and M. R. Squillante, "Characterization of polycrystalline $\mathrm{TlBr}$ films for radiographic detectors," IEEE Transactions on Nuclear Science, vol. 46, no. 3, pp. 266-272, 1999.

[4] F. E. Rosztoczy and D. Cubicciotti, "The bismuth iodide-iodine phase diagram," The Journal of Physical Chemistry, vol. 69, no. 1, pp. 124-127, 1965.

[5] D. Cubicciotti and F. J. Keneshea Jr., "The vapor pressures of BiIs over liquid bi-BiI ${ }_{3}$ solutions," The Journal of Physical Chemistry, vol. 63, no. 2, pp. 295-297, 1959.

[6] J. H. Kim and S. Blairs, "Sublimation study of $\mathrm{BiI}_{3}$ " The Journal of Chemical Thermodynamics, vol. 22, no. 8, pp. 803-814, 1990.

[7] D. Nason and L. Keller, "The growth and crystallography of bismuth tri-iodide crystals grown by vapor transport," Journal of Crystal Growth, vol. 156, no. 3, pp. 221-226, 1995.

[8] L. Fornaro, E. Saucedo, L. Mussio, A. Gancharov, and A. Cuña, "Bismuth tri-iodide polycrystalline films for digital Xray radiography applications," IEEE Transactions on Nuclear Science, vol. 51, no. 1, pp. 96-100, 2004. 

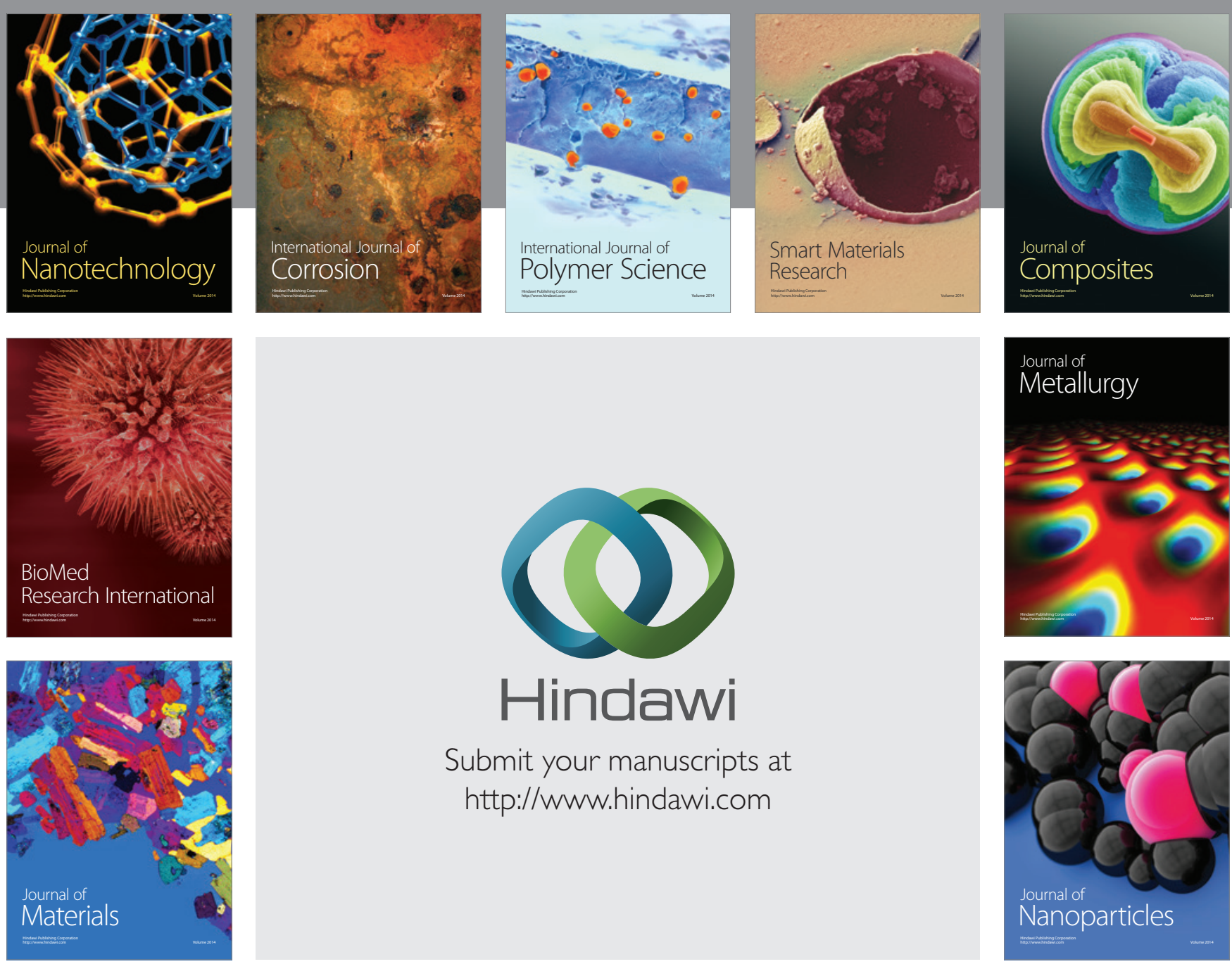

Submit your manuscripts at http://www.hindawi.com
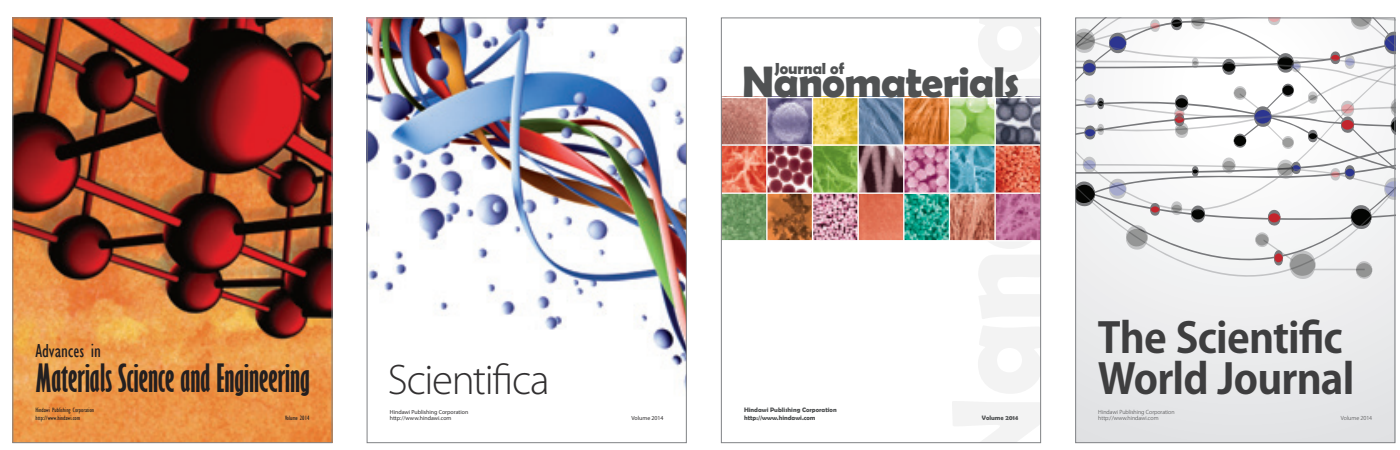

\section{The Scientific World Journal}
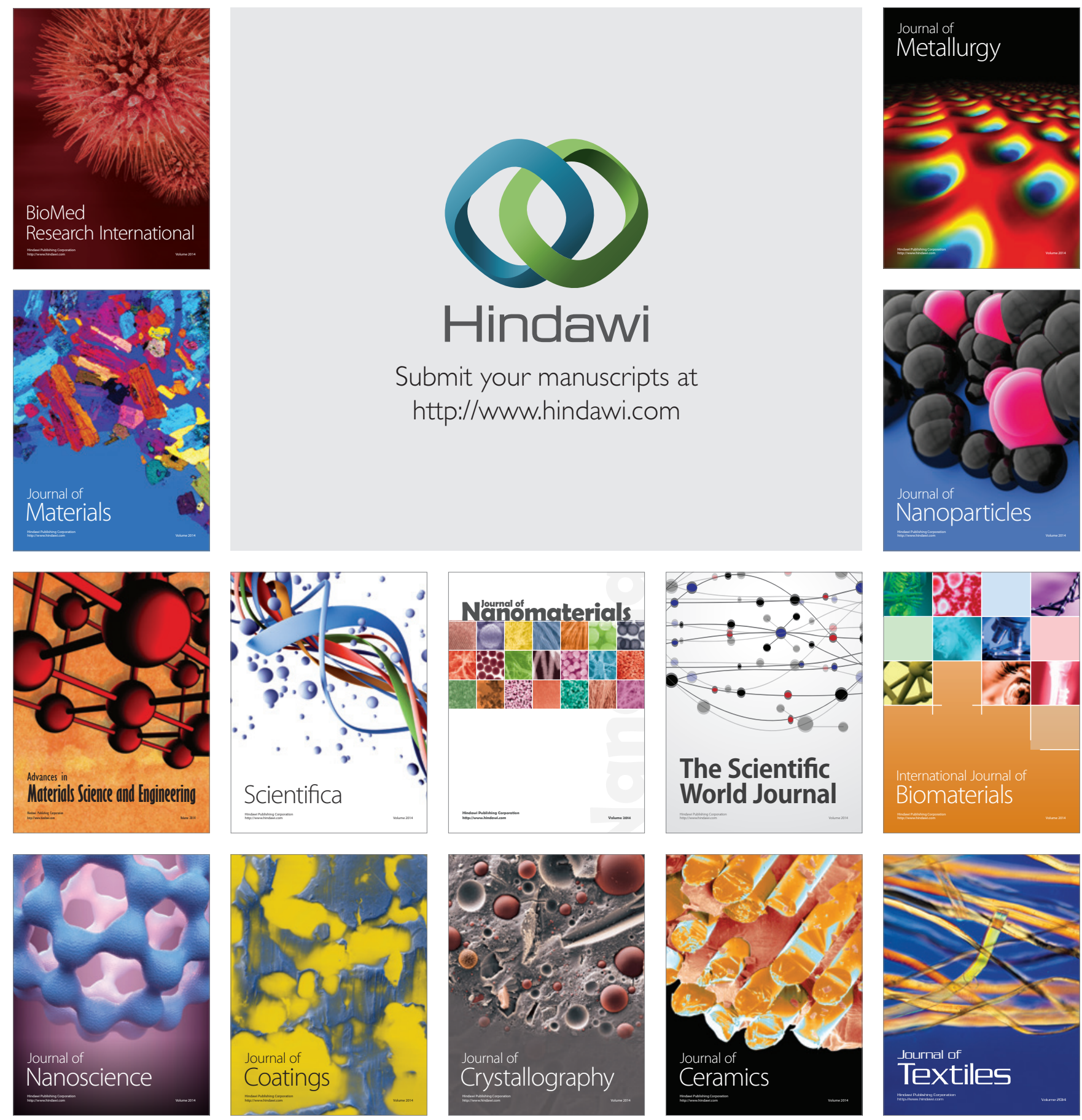